\title{
Aprendizagem de funçáo quadrática: uma proposta com auxílio do software Geogebra
}

\author{
Samuel Lopes Cerqueira ${ }^{1}$ \\ Rogério Fernando Pires ${ }^{2}$ \\ Zulma Elizabete de Freitas Madruga ${ }^{3}$
}

\section{Resumo}

Este artigo tem como objetivo apresentar uma proposta de intervenção de ensino com o auxílio do software Geogebra para a aprendizagem de funçáo quadrática no $9^{\circ}$ ano do Ensino Fundamental. O referencial teórico foi pautado nas ideias da teoria dos Registros de Representação de Raymond Duval, no tocante à articulação entre diferentes formas de registros. A metodologia consiste na elaboração de uma proposta de intervenção de ensino, na qual se apresenta uma abordagem de função quadrática com o auxílio do software Geogebra, à luz da Teoria dos Registros de Representaçáo Semiótica. Com isso, a proposta de intervenção visa um maior entendimento do conceito de função quadrática e a busca por uma apreensão global do conteúdo, a fim de que os estudantes possam dar prosseguimento aos seus estudos com um bom embasamento do conteúdo de função quadrática.

Palavras-chave: registros de representação semiótica; função quadrática; software Geogebra.

\section{Quadratic function earning: a proposal with the help of Geogebra software}

\section{Abstract}

This article aims to present a proposal of teaching intervention with the help of Geogebra software for the learning of quadratic function in the 9th year of Elementary School. The theoretical framework was based on the ideas of Raymond Duval's Theory of Representation Registers, regarding the articulation between different forms of registers. The methodology consists in the elaboration of a proposal of intervention of teaching, in which a quadratic function approach is presented with the aid of the Geogebra software, in light of the Theory of Registers Semiotics Representation. With this, the intervention proposal aims to provide a greater understanding of the concept of quadratic function, the search for a global apprehension of content so that students can continue their studies with a good foundation of quadratic function content.

Key-words: registers of semiotic representation; quadratic function; Geogebra Software.

1 Universidade Estadual de Santa Cruz - UESC. slopes54@yahoo.com.br.

2 Universidade Federal de Uberlândia - UFU.rfpires@ufu.br.

3 Universidade Federal do Recôncavo da Bahia - UFRB. betemadruga@ufrb.edu.br. 


\section{Introduçáo}

O conteúdo de funções é importante para o desenvolvimento do pensamento algébrico. Trata-se de um dos principais assuntos do bloco de conteúdos grandezas e medidas, presente nos Parâmetros Curriculares Nacionais - PCN (BRASIL, 1998), e reforçado pela Base Nacional Comum Curricular - BNCC (BRASIL, 2017, 2018).

Muitos alunos têm concluído o Ensino Médio sem possuir um domínio consistente da noção de função, em especial, a função quadrática, e acabam por chegar ao Ensino Superior sem terem o domínio do conteúdo e habilidades suficientes para resolver problemas relacionados a esse tema. Essa dificuldade na aquisição dos conhecimentos e da compressão do conceito de função é tema de pesquisas que visam compreender a causa das dificuldades na aprendizagem e propor possibilidades de superação. Dessa forma, o presente estudo procura propor um caminho que possa de certa forma contribuir para a construção dos conhecimentos referentes à função quadrática.

A importância deste tema instiga refletir sobre como o conceito de função quadrática está sendo ensinado a partir do $9^{\circ}$ ano do Ensino Fundamental, já que não se trata de um assunto exclusivo do Ensino Médio, pois ao verificar o fraco desempenho dos estudantes nas questóes que envolviam este conceito no SAEB, (Sistema Nacional de Avaliação da Educação Básica) e no ENEM (Exame Nacional do Ensino Médio), constata-se a afirmação.

Dessa forma, este artigo tem o objetivo de apresentar uma proposta de intervenção de ensino com o auxílio do software Geogebra para a aprendizagem de função quadrática no $9^{\circ}$ ano do Ensino Fundamental. O intuito é mostrar possibilidades de ensino do conteúdo de maneira dinâmica, e que possa auxiliar na aprendizagem de função quadrática.

\section{Os registros de representaçáo semiótica}

Diante da constante transformação científica e tecnológica, é necessário que os estudantes tenham uma formação matemática cada vez mais sólida, uma vez que os ambientes, principalmente os de trabalho, vêm se tornando cada vez mais informatizado.

De acordo com Duval (2011), o objetivo do ensino da Matemática é contribuir para o desenvolvimento geral de suas capacidades de raciocí- 
nio, de análise e de visualização. Para esse autor a originalidade de uma abordagem cognitiva não está em partir dos erros para tentar determinar as concepçóes dos alunos, e da origem de suas dificuldades nos campos da Matemática, mas sim, em procurar descrever inicialmente o funcionamento cognitivo que possibilite ao aluno compreender, efetuar e controlar ele próprio a diversidade dos processos matemáticos que lhe são propostos em situaçóes de ensino.

Duval (2011) afirma que a diferença entre a atividade cognitiva requerida pela Matemática e aquela requerida em outros domínios do conhecimento tais como, Astronomia, Biologia etc., não deve ser procurada nos conceitos. Para ele, todo domínio de conhecimento desenvolve um contingente de conceitos mais ou menos complexo.

O autor ressalta a importância das representaçóes semióticas na evolução do conhecimento matemático que depende do sistema de representação utilizado, destacando as possibilidades do tratamento matemático, dentre elas as operaçóes com o cálculo. O termo registro de representação, utilizado por Duval em sua teoria, refere-se aos diferentes tipos de representações semióticas mobilizáveis no funcionamento matemático. Duval (2003) apresenta quatro tipos de registros distintos, conforme fig. 1.

Figura 1 - Classificação dos diferentes registros mobilizáveis no funcionamento matemático.

\begin{tabular}{|c|c|c|}
\hline & REPRESENTAÇÃO DISCURSIVA & REPRESENTACC̈ÄO NÅO-DISCURSIVA \\
\hline $\begin{array}{l}\text { REGISTROS } \\
\text { MULTIFUNCIONAIS: } \\
\text { Os tralamentos nâo sắo } \\
\text { algorittmizáveis. }\end{array}$ & $\begin{array}{l}\text { Lingua natural } \\
\text { Associaçōes verbais (conceituais). } \\
\text { Forma de raciocinar. } \\
\text { - argumentaçäo a partir de } \\
\text { observaçoses, de crenças...; } \\
\text { - deduçāo válida a partir de } \\
\text { definiçäo ou de teoremas. }\end{array}$ & $\begin{array}{l}\text { Figuras geométricas planas ou em } \\
\text { perspectivas (confipuraçōes em } \\
\text { dimensăo } 0,1,2 \text { ou } 3 \text { ). } \\
\text { - apreensăo operatória e năo somente } \\
\text { perceptiva; } \\
\text { - construçāo com insirumentos. }\end{array}$ \\
\hline $\begin{array}{l}\text { REGISTROS } \\
\text { MONOFUNCIONAIS: } \\
\text { Os tratamentos săo } \\
\text { principalmente } \\
\text { algoritmos. }\end{array}$ & $\begin{array}{l}\text { Sistemas de escritas: } \\
\text { - numéricas (binária, decimal, } \\
\text { Iracionária...); } \\
\text { - akgébricas; } \\
\text { - simbólicas (linguas formais). } \\
\text { Cálculo }\end{array}$ & $\begin{array}{l}\text { Grálicos cartesiancs. } \\
\text { - mudanças de sistema de } \\
\text { coordenadas; } \\
\text { - interpolaçäo, extrapolaçăo. }\end{array}$ \\
\hline
\end{tabular}

Fonte: Duval (2003, p. 14). 
Dessa forma, um registro de representação pode dar origem a outros registros de representaçóes, por exemplo, considerando o registro algébrico de uma função quadrática $f(x)=x^{2}+x-2$, este pode dar origem a outro registro de representaçáo: o gráfico no plano cartesiano (figura 2).

Figura 2 - Gráfico da função $f(x)$.

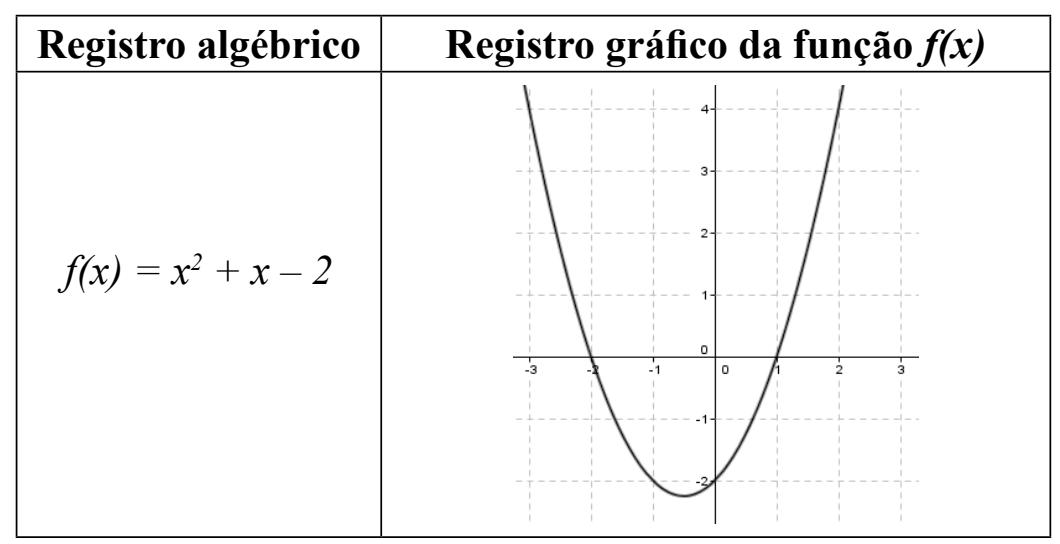

Fonte: Os autores (2019).

Para Duval (2003), a originalidade da atividade matemática está na mobilização de ao menos dois registros de representação ao mesmo tempo, passando de um registro para o outro, e isso leva à conjectura de que a compreensão em Matemática se dá a partir do domínio de pelo menos dois registros de representação semiótica.

$\mathrm{O}$ autor afirma que existe uma diferença chave para analisar a atividade matemática em uma perspectiva de aprendizagem e que existem dois tipos de transformações de representações semióticas radicalmente diferentes: os tratamentos e as conversóes. Enquanto os tratamentos consistem em transformaçóes de representaçóes dentro de um mesmo registro, as conversôes são transformaçóes de representaçóes que consistem em mudar de registro conservando o mesmo objeto denotado.

Um exemplo de um tratamento ocorre na resolução de uma equação, já uma conversão seria passar da escrita algébrica da equação para a sua representação gráfica. Duval (1988) diz que as conversóes são as formas mais simples de tratamento, considerando a conversão como uma associação preestabelecida entre nomes e figuras, dessa forma reduzindo-a a uma codifica- 
ção. Por exemplo, passar de uma expressão em português, como o conjunto dos pontos cuja ordenada é maior do que a abscissa, a escrita simbólica, $\mathrm{x}>$ y, isto seria algo pontual.

Segundo o autor, a regra de codificaçáo permite apenas uma leitura pontual das representaçóes gráficas, não permite uma apreensão global e qualitativa. $\mathrm{O}$ autor afirma que essa apreensão é necessária para extrapolar, interpolar ou para utilizar os gráficos para fins de controle relacionados ao tratamento algébrico, ou seja, quando por meio da representação gráfica é possível explorar diversas propriedades que vão além do traçado do gráfico, por exemplo, a relaçáo entre o coeficiente $a$ e a concavidade da parábola. A seguir, na figura 3, Duval (2003) faz um esquema da organização semiótica e do funcionamento das representaçóes gráficas, sugerindo um possível caminho para se alcançar a apreensão global do objeto matemático em estudo.

Figura 3 - Esquema de organização semiótica e do funcionamento das representaçóes gráficas.

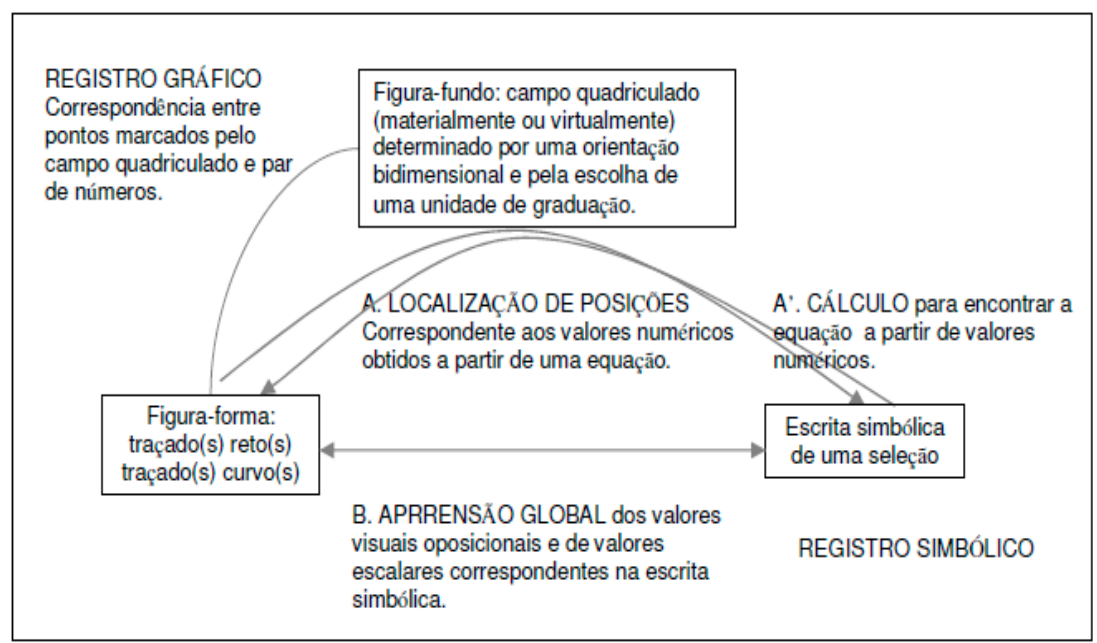

Fonte: Duval (2003, p. 18).

De acordo com Duval (2003, p. 18):

Essa organização permite três tipos de tratamentos (isto é, operaçóes internas aos gráficos) e dois tipos de conversão com o registro simbólico. As ligações entre A e A' permitem também uma leitura pontal dos 
gráficos. Somente a coordenação B permite uma apreensão global qualitativa.

Duval (1988) afirma que o fracasso e os bloqueios dos alunos na aprendizagem, aumentam consideravelmente cada vez que uma mudança de registro é necessária ou que a mobilização de dois registros de representação é requerida. "A originalidade da atividade está na mobilização simultânea de ao menos dois registros de representação ao mesmo tempo, ou na possibilidade de trocar o todo momento de registro de representação" (DUVAL, 2003, p. 14).

Dessa forma, o autor menciona que a compreensão em Matemática implica a capacidade de mudar de registro, e mais, não se deve jamais confundir o objeto e sua representação, já que o acesso aos objetos matemáticos passa necessariamente por representaçōes semióticas.

Pode-se então concluir que a compreensão em Matemática está em manipular dois registros ao mesmo tempo, passando de um para o outro, mudando o tratamento, mas também sabendo explicar as propriedades do objeto.

\section{O uso das tecnologias na sala de aula}

Pesquisadores em Educação Matemática têm buscado meios que favoreçam o ensino e a aprendizagem, e as Tecnologias de Comunicaçáo e Informação (TIC) têm sido um dos temas que promovem diversas discussóes e motivam várias pesquisas na área.

De acordo com Lemos (2013), o uso das Tecnologias da Comunicação e Informação é fortemente indicado na literatura especializada, como recurso didático para promover aulas inovadoras. Dessa forma, a promoção de aulas de Matemática mais interessantes, com o uso das TIC, vem ganhando destaque, surgindo como recurso didático que auxilia o professor em suas aulas e facilita a compreensão do estudante. Diante disso, surge então uma inquietação: Será que os professores possuem uma formação que lhes permita a utilização de meios tecnológicos como o computador, enquanto um recurso didático?

Segundo Borba e Penteado (2007), alguns professores procuram caminhar em uma zona de conforto onde quase tudo é conhecido, previsível e controlável. Muitos reconhecem que a forma como estão atuando não favo- 
rece a aprendizagem, e mantém o discurso dizendo que gostariam que fosse diferente, embora não façam esforços para mudar aquilo que não os agrada. Dessa forma, permanecem nesta zona e não procuram caminhos que possam gerar incertezas e imprevisibilidades, não avançando para a chamada zona de risco, na qual seria preciso avaliar constantemente as consequências de suas ações, exigindo de cada professor, mais estudos e formação continuada.

De acordo com Borba e Penteado (2007), ao realizar atividades em ambientes informatizados, além de trazer a visualização para o centro da aprendizagem matemática, enfatiza-se a experimentação. As novas mídias, como computadores com software gráficos e calculadora gráfica, permitem aos estudantes essa experimentação.

Dessa forma, ao passo que as construções são feitas pelo software, sobre algum tema proposto pelo professor, surgem também conjecturas locais, levantadas em sala de aula, e estas devem ser debatidas. Com isso, podemos dizer que as conjecturas são frutos do enfoque experimental com tecnologias e surgem a partir da investigação com as calculadoras e computadores equipados com softwares.

A interlocução entre Matemática e tecnologia é necessária. É importante promover a construçáo de um pensamento crítico, reflexivo, de forma que os estudantes se apropriem dos conceitos matemáticos, se posicionem perante os resultados encontrados e reflitam sobre o que fizeram. $\mathrm{O}$ uso de recursos alternativos que busquem uma melhora no ensino de Matemática constitui um meio a ser utilizado para obter bons resultados na aprendizagem.

Nesta proposta de intervenção, é sugerida a utilização do software Geogebra, criado e desenvolvido por Markus Hohenwater, professor e pesquisador da área de informática aplicada à Educação Matemática, da universidade de Salzburg, na Áustria. O Geogebra é um software gratuito de Matemática dinâmica, que possibilita trabalhar geometria, álgebra e cálculo. Este software foi escolhido por ser de fácil manipulação, pelo seu dinamismo, e por ser gratuito. Como aplicativo de geometria dinâmica, o Geogebra oferece a possibilidade de construção de várias representaçóes gráficas em um mesmo plano, algo praticamente impossível no ambiente papel e lápis. 


\section{Metodologia}

Esta pesquisa é de cunho qualitativo, o que, segundo Creswell (2010), é um meio de explorar e de entender o significado que os indivíduos ou grupos atribuem a um problema social ou humano. O processo de pesquisa envolve questóes e procedimentos emergentes; coletar dados no ambiente dos participantes; analisar os dados indutivamente, indo de temas particulares para os gerais; e fazer interpretaçóes dos significados dos dados.

Este estudo tem a finalidade de elaborar e propor um conjunto de atividades, que compóem uma intervenção de ensino que posteriormente poderá ser aplicada em sala de aula. As atividades consistem no estudo da função quadrática com auxílio do software Geogebra, à luz da Teoria dos Registros de Representação de Raymond Duval. Mostra-se, a partir da dinâmica do software Geogebra, a importância dos tratamentos e conversóes no processo de compreensão do conteúdo das funções quadráticas, visando alcançar uma apreensão global e qualitativa do objeto matemático em estudo.

Esta intervenção de ensino consiste em uma proposta que poderá ser aplicada em sala de aula ou no laboratório de informática, ambos com a utilização de computadores e do software Geogebra. Com a finalidade de se estudar mais profundamente a função quadrática, em especial, suas representaçóes gráficas, discutir-se-á a relaçáo entre os coeficientes do registro algébrico de $f(x)=a x^{2}+b x+c$, com o formato da parábola que representa graficamente tal função.

Para introduzir atividades com o conteúdo das funçóes quadráticas será preciso que os estudantes já tenham certo nível de conhecimento acerca de alguns assuntos como função afim, equaçóes do primeiro grau, e equações de segundo grau.

O foco desta proposta consiste no estudo de representaçóes gráficas das funçôes quadráticas, bem como a variação dos coeficientes $(a, b, c)$ no registro algébrico e sua implicação no registro gráfico, difíceis de fazer no ambiente papel e lápis. Os estudantes, com a orientação do professor, irão desenvolver dentro do ambiente computacional esta proposta, ampliando assim as discussóes em torno da função quadrática. Além disso, temas como os registros de representação semiótica podem ser discutidos em sala de aula.

Com isso, espera-se que, ao ser aplicada em sala de aula, essa proposta possibilite aos estudantes uma melhor capacidade para ler e interpretar gráficos com maior facilidade, além de reconhecer e extrair das representaçóes 
gráficas informações importantes quanto à natureza da função quadrática e como ela é representada.

\section{Proposta de intervençáo de ensino}

Esta proposta de invenção de ensino consiste no estudo das funções quadráticas com auxílio do software Geogebra. Serão estudadas as funçóes quadráticas, cujas representaçóes algébricas são do tipo: $\mathrm{f}(\mathrm{x})=\mathrm{ax}^{2}$, com $\mathrm{a} \neq$ $0, a \in R, f(x)=a x^{2}+c$, coma $\neq 0$, a e cє $R, f(x)=a(x-m)^{2}$ com $a \neq 0$, $a$, $\mathrm{m} \epsilon \mathrm{R}$ e $\mathrm{f}(\mathrm{x})=\mathrm{ax}^{2}+\mathrm{bx}+\mathrm{c}$, com $\mathrm{a} \neq 0$, $\mathrm{a}, \mathrm{b}$ e cє $\mathrm{R}$. Em todos os casos os parâmetros $a, b$ e $c$ pertencem aos reais, por definição e por estar tratando de funçôes quadráticas, o parâmetro $a$ é diferente de 0 .

Nesta proposta, serão construídos os gráficos das respectivas funções, o estudo dos parâmetros $a, b$ e $c$, identificando as raízes das funçóes; o vértice da parábola; a orientação da concavidade da parábola; se há simetria na representação gráfica; e propondo a busca por generalizaçóes a partir da análise dos gráficos.

Os estudos e as análises a partir do ambiente computacional irão facilitar as conclusóes dos alunos acerca das implicaçóes entre as unidades simbólicas significativas e as variáveis visuais, como apresenta Duval (1998) em sua teoria. Dentre essas variáveis visuais, podemos citar a orientação da parábola, que depende do sinal do coeficiente $a$; a variação da abertura da parábola, que também depende do valor associado ao parâmetro $a$; como também o reconhecimento das implicaçóes geradas no registro gráfico das funções a partir da variação dos parâmetros $b$ e $c$ no registro algébrico.

Espera-se que a manipulação destas variáveis, através do ambiente computacional, possibilite aquilo que Duval (1998) chama de apreensão global do objeto matemático, alcançado através da mobilização das diferentes formas de registro do mesmo objeto e investigando suas características.

\section{Apresentação e discussão das atividades}

A primeira atividade corresponde ao estudo do parâmetro " $a$ ", que compóe a função quadrática. Nesta atividade os estudantes irão construir os gráficos de funçóes do tipo $f(x)=a x^{2}, \operatorname{com} a \neq 0$, $a \in \mathrm{R}$, serão atribuídos valores reais ao parâmetro $a$, os gráficos serão construído num mesmo plano cartesiano para melhor visualização e análise do comportamento do gráfico 
pela variação do parâmetro " $a$ ", e serão analisadas as raízes, a concavidade, a abertura da parábola.

\section{Atividade 1}

1. Em um mesmo par de eixos cartesianos desenhe, utilizando o Geogebra, o gráfico das seguintes funções:
a) $f 1(x)=x 2$
f) $f 6(x)=-5 \times 2$
b) $f 2(x)=2 x 2$
g) $f 7(x)=-2 x 2$
c) $f 3(x)=5 \times 2$
h) $f 8(x)=-x 2$
d) $f 4(x)=x 2$
i) $f 9(x)=-x 2$
e) $f 5(x)=x 2$
j) $f 10(x)=-x 2$

\section{Análise dos gráficos:}

a) O que se pode concluir quando o coeficiente " $a$ " é maior do que zero? E quando ele é menor do que zero?

b) Existe algum ponto em comum em todos os gráficos? Qual seria?

c) $\mathrm{O}$ que se pode concluir a respeito do valor absoluto do parâmetro $a$, quanto à abertura da parábola?

d) Utilizando o comando controle deslizante, insira no campo de entrada do Geogebra a representação algébrica da função quadrática $g(x)=$ $a^{*}\left(x^{\wedge} 2\right)$, e selecione a opção criar controle deslizante para $a$.

Em seguida clique com o botáo direito do mouse no ícone, referente ao parâmetro $a$, e selecione a opção animar. Observe o que irá acontecer com a representação gráfica da função $\mathrm{g}(x)$ à medida que o parâmetro assume diferentes valores, observe a orientação da parábola, e veja o que acontece com a abertura da parábola à medida que o valor absoluto do parâmetro $a$ aumenta (figura 4). O que se pode concluir diante dessas diferentes representaçóes a partir da variação do parâmetro $a$ ? 
Figura 4 - Representação das funções da primeira atividade

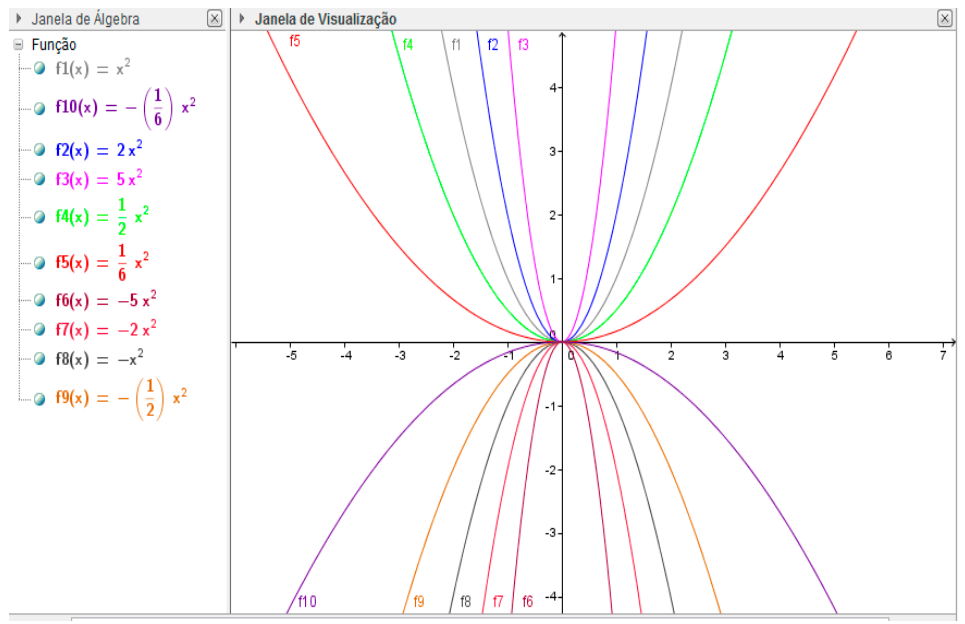

Fonte: Os autores (2019).

A partir das construçóes e posterior análises das atividades, feitas pelos estudantes juntamente com o professor, pode-se chegar a algumas conclusôes acerca do que foi estudado. Como se tratam de funçóes do tipo $a x^{2}$, todas elas vão apresentar as mesmas raízes - neste caso será 0 , sendo o ponto $(0,0)$ comum para todas as funçóes.

- Quando a > 0, a concavidade está voltada para cima;

- Quando a $<0$, a concavidade está voltada para baixo;

- Todas as parábolas têm o mesmo vértice $(0,0)$ e o mesmo eixo $\mathrm{x}=0$;

- Quanto menor o valor absoluto de a, maior será a abertura da parábola;

- Quanto maior o valor absoluto de a, menor será a abertura da parábola;

- Os gráficos das funçóes quadráticas $f(x)=a x^{2}$ e $g(x)=a^{\prime} x^{2}$, em que a e a' são números simétricos em relação ao eixo $\mathbf{x}$.

A segunda atividade refere-se ao estudo da função quadrática, com representação algébrica do tipo $f(x)=a x^{2}+c$, com $a \neq 0, a, c \in \mathrm{R}$. Nesta atividade é estudada a variaçâo da parábola a partir do parâmetro " $c$ ", em que são identificados os vértices, a concavidade e as raízes. Nessas atividades são construídos gráficos em uma janela do Geogebra. Com isso, ao final das construçóes será possível chegar a uma generalização a respeito da representação algébrica das funções. 


\section{- Atividade 2}

1. Em um mesmo plano cartesiano, construa os gráficos das funções das seguintes representaçôes algébricas.
a) $f_{1}(x)=-x^{2}$
b) $f_{3}(x)=-x^{2}-1$
c) $f_{2}(x)=-x^{2}+1$
d) $f_{4}(x)=-x^{2}-2$
e) $f_{5}(x)=-x^{2}+2$

2. O que acontece com a função inicial $f_{1}(x)=-x^{2}$ quando se soma ou se subtrai um valor inteiro a ela para obter uma nova função?

3. Quais as coordenadas do vértice de cada função? O que se pode concluir acerca do coeficiente "c" na determinação do vértice da parábola nesse tipo de função?

4. Novamente, usa-se o comando controle deslizante para visualizar a translação horizontal da representação gráfica da função quadrática $g(x)=$ $-x^{\wedge} 2+c$, digitando no campo de entrada a função $g(x)$, e confirmando em criar controle deslizante para $c$. Observa-se o que acontece com a representação gráfica da parábola à medida que o parâmetro $c$ varia (figura 5).

Figura 5 - Gráficos das funções da segunda atividade

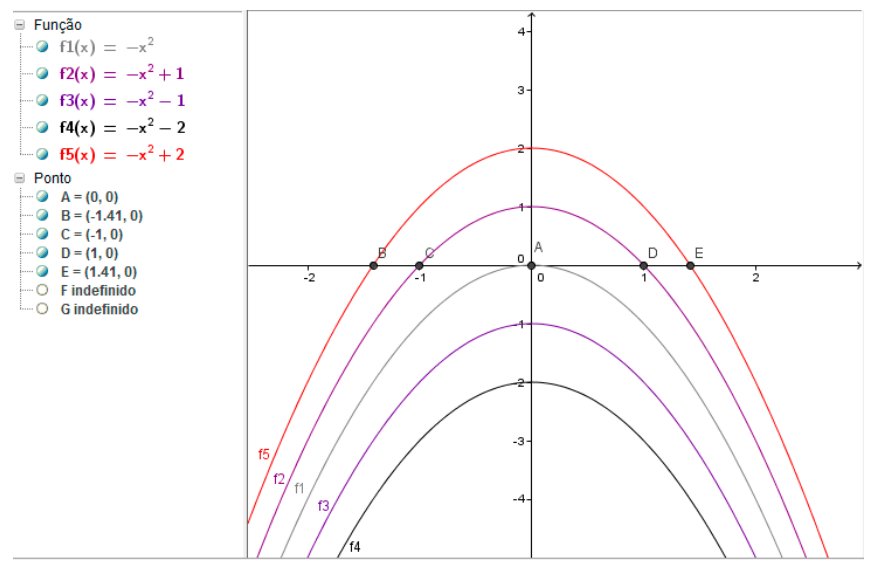

Fonte: Os autores (2019). 
Nesta situação, os alunos estarão construindo os gráficos no Geogebra, determinando suas raízes, os vértices das parábolas e analisando a concavidade das parábolas. Como o vértice de uma parábola coincide com o valor de máximo ou de mínimo de uma funçáo quadrática, e ele é do tipo ( $x, y)$, em que $\mathrm{x}$ é a abscissa e y é a ordenada, nesta situação os estudantes irão identificar no gráfico os possíveis pontos máximos de cada função, utilizando o ambiente papel e lápis para calcular as coordenadas a partir dos conhecimentos adquiridos em aulas anteriores, e depois comparar os resultados. Há situações em que algumas funções não têm raízes reais, com isso o comando do Geogebra irá indicar indefinido quanto a essas raízes.

As funções $f_{1} ; f_{2} ; f_{3} ; f_{\dot{4}} f_{5}$ apresentam seus respectivos pontos Máximos nesta ordem: $(0,0) ;(0,1) ;(0,-1) ;(0,-2) ;(0,2)$. Pode-se observar que as funçóes $f_{3}$ e $f_{4}$ não possuem raízes reais, pois a parábola não intercepta o eixo em nenhum ponto. Outro fator importante é a orientação da parábola. Observa-se que todas elas estáo voltadas para baixo, o que indica que o coeficiente é $a<0$.

A análise dos gráficos permite aos estudantes chegar a conclusóes importantes quanto aos pontos máximo ou mínimo, partindo da análise do parâmetro " $c$ ". Ainda, tomando como base a função $f_{l}$, podem-se comparar todos os pontos máximos das funçóes em estudo e buscar uma generalização tanto para $\mathrm{a}>0$ quanto para $\mathrm{a}<0$.

Observa-se que o gráfico de $f(x)=a x^{2}+c$ é congruente ao gráfico de $f(x)=a x^{2}$, porém sua posição é, em valores absolutos, $k$ unidades acima ou abaixo. Conforme $k$ seja positivo ou negativo, a parábola sofre uma translação vertical em relação ao eixo $\mathrm{y}$, quando há variaçáo do parâmetro $c$. A parábola intercepta o eixo y no ponto $(0, c)$. Neste caso, com $\mathrm{a}<0$, o ponto máximo de $f(x)=a x^{2}+c$ é $(0, c)$.

A terceira atividade refere-se ao estudo e construção das funções quadráticas do tipo $f(x)=a(x-m)^{2}$, com $a \neq 0$, e $a, m \in$ R. Eles identificarão os vértices, as raízes, a concavidade da parábola, e discutirão a simetria da parábola em relação à reta $\mathrm{x}=\mathrm{m}$.

\section{Atividade 3}

1. Em um mesmo plano cartesiano, construa no Geogebra o seguinte gráfico das funçóes: 

a) $f_{1}(x)=x^{2}$
b) $f_{2}(x)=(x+2)^{2}$
c) $f_{3}(x)=(x-2)^{2}$
d) $f_{4}(x)=(x-1)^{2}$
e) $f_{5}(x)=(x+1)^{2}$

2. Compare os gráficos a partir da primeira função. O que acontece quando se soma ou se subtrai uma constante à variável independente?

3. O que se pode concluir, de maneira generalizada, a respeito dos vértices dessas parábolas?

4. Usando o comando controle deslizante para visualizar as variações nas representaçóes, insira no campo de entrada a função $h(x)=(x-m)^{\wedge} 2$, e confirme criar controle deslizante para $m$. (figuras 6 e 7).

Figura 6 - Gráficos das funções da terceira atividade

$$
\begin{aligned}
& \text { Janela de Álgebra } \\
& \mathbf{f u n c ̧ a ̃ o} \\
& \mathbf{f 1}(\mathrm{x})=\mathrm{x}^{2} \\
& \mathrm{f} 2(\mathrm{x})=(\mathrm{x}+2)^{2} \\
& \mathrm{f3}(\mathrm{x})=(\mathrm{x}-2)^{2} \\
& \mathrm{f} 4(\mathrm{x})=(\mathrm{x}-1)^{2} \\
& \mathrm{f5}(\mathrm{x})=(\mathrm{x}+1)^{2} \\
& \text { Ponto } \\
& \mathrm{A}=(0,0) \\
& \mathrm{B}=(-2,0) \\
& \mathrm{C}=(2,0) \\
& \mathrm{D}=(1,0) \\
& \mathrm{E}=(-1,0)
\end{aligned}
$$

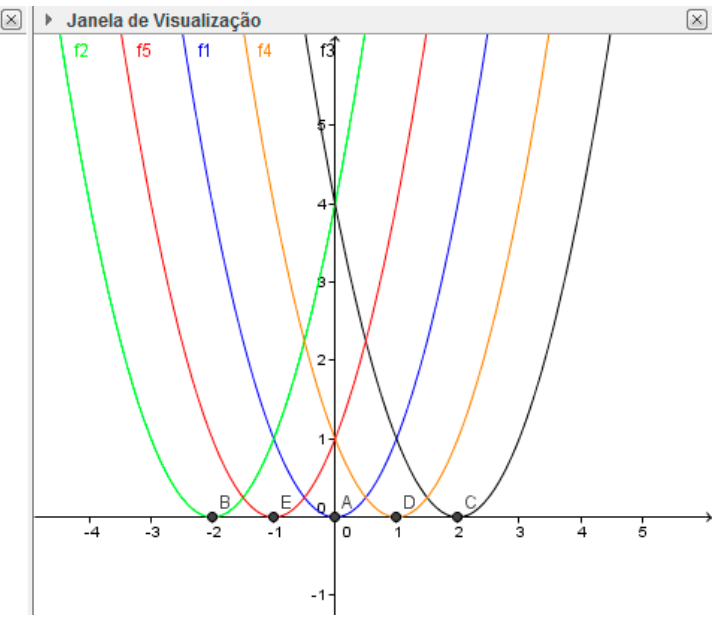

Fonte: Os autores (2019). 
Figura 7 - Gráficos com eixo de simetria

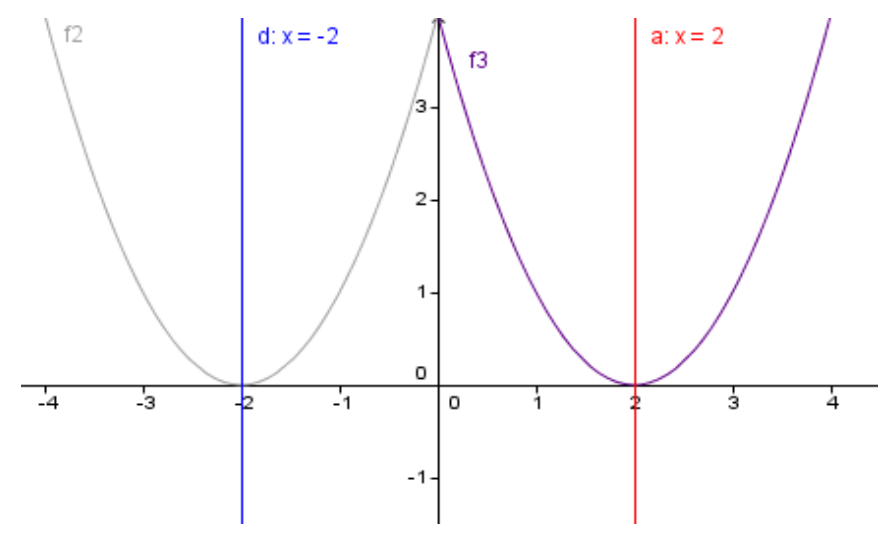

Fonte: Os autores (2019).

A construção dos gráficos no Geogebra permite aos estudantes uma melhor visualização e uma análise mais detalhada, pois os gráficos estarão num mesmo plano. Como nos exercícios anteriores, as raízes, o vértice, a abertura da parábola, sua orientação, e posicionamento serão alvo de estudo nesta atividade.

Observa-se que os gráficos são todos congruentes. De modo geral o gráfico de $f(x)=a(x-m)^{2}$ é congruente ao gráfico de $g(x)=a x^{2}$, porém sua posição em valores absolutos é $m$ unidades à direita ou à esquerda do gráfico de $g(x)=a x^{2}$, conforme $m$ seja positivo ou negativo. Dessa forma, ao somar ou subtrair a função $g(x)$, o gráfico sofre uma translação horizontal em relação ao eixo $x$. Considerando a função $f(x)=x^{2}$, observa-se que ao somar +2 , ao fator x e elevar ao quadrado, se obtém $f(x)=(x+2)^{2}$, o gráfico de $f(x)=x^{2}$ sofre uma translação horizontal à esquerda, variando assim a posição do vértice, que passa a ser $(-2,0)$.

Se a $>0$, a concavidade da parábola está voltada para cima e ela tem um ponto mínimo $(m, 0)$. Se a $<0$, a concavidade é para baixo e a parábola tem um ponto máximo $(\mathrm{m}, 0)$. Isso ocorre por que essas equaçóes têm raízes duplas iguais.

O gráfico da Figura 7 é simétrico em relação à reta $x=m$, e essa reta é o eixo da parábola. Observa-se que, ao considerar pontos equidistantes da origem, estes irão possuir mesma imagem pela função, logo a reta $x=m$ divide a parábola em duas partes simétricas. 
$\mathrm{Na}$ quarta atividade, iremos trabalhar com a função quadrática na forma $f(x)=a x^{2}+b x+c$, construindo gráficos, descobrindo o vértice, as raízes, a orientação da parábola e o discriminante da função.

\section{Atividade 4}

Dadas as funçōes quadráticas

$$
f(x)=x^{2}-4 x+4 ; g(x)=x^{2}-6 x+5 ; h(x)=-x^{2}-4 x-6
$$

a) Determinar no ambiente papel e lápis, as raízes, o discriminante e o vértice de cada uma das funções.

b) Esboçar o gráfico de cada uma com ajuda do software Geogebra (figura 8).

c) Em quantos pontos do eixo OX, o gráfico de cada uma das funçôes intersecta?

d) Quantas raízes reais têm as funções representadas em $f, g$ e $h$ ? Qual a relação entre o discriminante e o número de raízes de uma função quadrática?

Figura 8 - Gráfico das funçóes da atividade 4

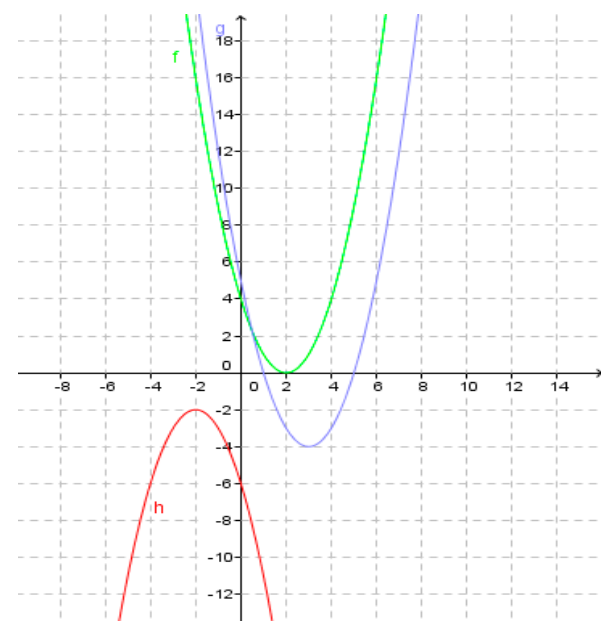

Fonte: Os autores (2019).

Nesta atividade temos duas funçóes com a parábola voltada para cima, e uma com parábola voltada para baixo. Cada uma delas tem características importantes: a função $\boldsymbol{g}$ intercepta o eixo $\mathrm{x}$ em dois pontos distintos. Esses pontos certamente são as raízes dessa função. Ao se obter o discriminante, observa-se que este é maior que zero. Logo, as raízes da função $\boldsymbol{g}$ são $\{0,2\}$, seu discriminante $\Delta=16$, e seu vértice é $(3,-4)$. 
Já a função $\mathbf{f}$ não chega a interceptar o eixo $\mathrm{x}$, mas toca em apenas um ponto. Este ponto então será a sua raiz $\{2\}$. Neste caso, f possui uma raiz dupla, se observamos seu discriminante, este é igual a zero. $O$ vértice de $\mathbf{f}$ são os pontos $(2,0)$. Até agora, pode-se afirmar que, se o discriminante existe e é maior ou igual a zero, então a função possui raízes reais. Na função $\boldsymbol{b}$, a parábola não toca no eixo $\mathrm{x}$. Se o discriminante desta função for observado, é possível perceber que ele é menor que zero, e isto nos diz que ela não possui raiz real, por isso, a parábola náo toca no eixo $\mathrm{x}$.

\section{Algumas reflexóes e consideraçóes}

Este artigo teve como objetivo apresentar uma proposta de intervenção de ensino com o auxílio do software Geogebra para a aprendizagem de função quadrática no $9^{\circ}$ ano do Ensino Fundamental. Ao longo da revisão de literatura, perceberam-se os esforços que vários pesquisadores, atuantes na área da Educação Matemática, tem feito para entender as dificuldades que muitos alunos apresentam em sala de aula acerca de diversos assuntos, dentre eles o de funçóes quadráticas. Os pesquisadores procuram compreender as dificuldades e propor possíveis meios para que estas sejam superadas.

Pode-se perceber que o uso das Tecnologias da Comunicação e Informação em sala de aula pode se apresentar como aliado no processo de ensino e aprendizagem da Matemática, mas para isso é preciso um bom planejamento didático da aula a ser ministrada, formaçáo profissional continuada e capacitação do professor para usar as tecnologias em sala de aula. Todas essas açóes podem contribuir para que situaçóes adversas não venham comprometer o andamento da aula.

Propor um ensino de Matemática atrativo, que desperte a curiosidade, que prenda a atenção do estudante, que busque a investigaçáo, a articulação entre os conhecimentos e possibilite a experimentação, vem se tornando cada vez mais difícil. Sair da zona de conforto não é fácil, principalmente para aqueles professores que concluíram suas licenciaturas há muito tempo, e que não acompanharam as mudanças, não buscaram capacitaçóes ou formação continuada. Todas essas situaçóes são empecilhos que devem ser superados para que se tenha um ensino mais eficiente e objetivo.

Neste estudo inicial, pode-se observar que a utilização dos recursos tecnológicos pode ser proveitosa. Tais recursos, quando bem aplicados ao ensino de Matemática, com um bom planejamento, podem proporcionar uma apre- 
ensão global e qualitativa do objeto matemático em estudo. Este tipo de apreensão, segundo Duval (1988), envolve a identificação das variáveis pertinentes e visuais que compóem as possíveis representaçóes de cada objeto. A compreensão dessas variáveis constitui um passo importante no desenvolvimento cognitivo do estudante, no desenvolvimento do raciocínio matemático.

Cada questão que compóe esta proposta de intervenção tem por objetivo chegar a conclusóes e generalizaçóes de acordo com processo de investigação proposto em cada uma das atividades. Procuramos mostrar a importância dos registros de representação na apreensão do conhecimento matemático, mostrar que um objeto matemático pode ser representado de diferentes maneiras que preservam a natureza e características do objeto.

Dessa forma, espera-se que a aplicaçáo desta proposta de intervenção de ensino em sala de aula possa proporcionar uma significativa evolução no entendimento dos estudantes, no que se refere ao conteúdo de função. Nesse sentido, como perspectiva de continuidade deste estudo, pretende-se aplicar estas atividades com estudantes do $9^{\circ}$ ano do Ensino Fundamental, e verificar a real eficácia desta proposta por meio de uma investigação qualitativa.

\section{Referências}

BRASIL. Secretaria de Educação Fundamental. Parâmetros Curriculares Nacionais: Matemática. Brasília: MEC/SEF, 1998.

BRASIL, Base Nacional Comum Curricular. Disponível em: http:// basenacionalcomum.mec.gov.br/wp-content/uploads/2018/02/bncc20dez-site.pdf. Acesso em: 18 de outubro de 2018.

BRASIL, Base Nacional Comum Curricular (BNCC) com a inclusão do Ensino Médio. Disponível em: http://basenacionalcomum.mec.gov.br/ bncc-ensino médio \& grqid=usO-gc6c\&=1\&hl=pt-BR\&geid=1053. Acesso em: 16 de maio de 2019.

BORBA, M. C.; PENTEADO, M.; G. Informática e Educação - 3. ed. 2. reimp. - Belo Horizonte: Autêntica, 2007.

CRECWELL, J.W, Projeto de pesquisa: Método qualitativo, quantitativo e misto. Tradução Magda Lopes; Porto Alegre: Artmed, 2010.

DUVAL, R. Graphiquesetequations: L'articulation de deux registres. Annales de Didactique et de Sciences cognitive, v. 1, p. 235-253, 1988. 
Registros de representaçóes semiótica e funcionamento cognitivo da compreensão matemática. In: MACHADO, S. D. A. (org.) Aprendizagem em matemática: Registros de representação semiótica. Campinas: Papirus, 2003. p. 11-33.

- Semiósis e pensamento humano: registro semiótico e aprendizagens intelectuais. Trad.: Lênio Fernandes Levy e Marisa Rosâni Abreu da Silveira. São Paulo: Editora Livraria da Física, 2009.

- Ver e ensinar matemática de outra forma: Entrar no modo matemático de pensar os registros de representação semiótica. In: Campos, T. M. M. (org.). Trad.: Marlene Alves Dias. São Paulo: PROEM, 2011.

LEMOS, J. A. S. J. Estudo de Funçóes Afins e Quadráticas com o auxílio do Computador. Campina Grande, 2013.

Recebido em: 23 ago. 2019.

Aceito em: 23 fev. 2020. 